\title{
Urban Geography \\ The role of spatial planning in transitioning to circular urban development --Manuscript Draft--
}

\begin{tabular}{|c|c|}
\hline Full Title: & The role of spatial planning in transitioning to circular urban development \\
\hline Article Type: & Debates and Interventions \\
\hline Keywords: & circular cities; circular economy; Spatial Planning; resources; sustainability \\
\hline Abstract: & $\begin{array}{l}\text { Circular urban development necessitates the socio-ecological transformation of our } \\
\text { urban systems. It requires that "wasted" resources are looped; the ecological } \\
\text { regenerative capacity and adaptive capacity of urban systems (infrastructure, form and } \\
\text { communities) are developed. The end result will be healthier urban ecosystems, with } \\
\text { low levels of resource consumption and wastage. } \\
\text { Spatial planning potentially has a crucial role to play in the delivery of circular urban } \\
\text { development. However, it has an ambiguous legacy, as demonstrated by case studies } \\
\text { in London, Paris and Amsterdam. Spatial planning will need to go beyond the } \\
\text { allocation of temporary spaces for circular experimentation, if it is to enable the } \\
\text { transition. It will need to intervene in markets to provide space for low-value, circular } \\
\text { activities. This will also enable the localised looping of resources through the co- } \\
\text { location of producers and consumers of "waste" within city-regions. } \\
\text { Spatial planning should further intervene, by supporting the infrastructure required to } \\
\text { implement circular actions and ensuring that urban form continues to support the } \\
\text { systems adopted. Planners can create demand for circular activities and products } \\
\text { through requirements placed on new developments. Thus, spatial planning will be } \\
\text { critical to the socio-ecological transformation, required in urban systems, to deliver } \\
\text { circular development. }\end{array}$ \\
\hline Order of Authors: & Joanna Williams \\
\hline Response to Reviewers: & I have made the mnor ammendements as requested to the text \\
\hline
\end{tabular}




\section{The role of spatial planning in transitioning to circular urban development}

Circular urban development necessitates the socio-ecological transformation of our urban systems. It requires that "wasted" resources - materials, water, heat, land and infrastructure - are looped; the ecological regenerative capacity and adaptive capacity of urban systems (infrastructure, form and communities) are developed. The end result will be healthier urban ecosystems, with low levels of resource consumption and wastage.

Spatial planning potentially has a crucial role to play in the delivery of circular urban development. However, it has an ambiguous legacy, as demonstrated by case studies in London, Paris and Amsterdam. Spatial planning will need to go beyond the allocation of temporary spaces for circular experimentation, if it is to enable the transition. It will need to intervene in markets to provide space for low-value, circular activities. This will also enable the localised looping of resources through the co-location of producers and consumers of "waste" within city-regions.

Spatial planning should further intervene, by supporting the infrastructure required to implement circular actions and ensuring that urban form continues to support the systems adopted. Planners can create demand for circular activities and products through requirements placed on new developments. Thus, spatial planning will be critical to the socio-ecological transformation, required in urban systems, to deliver circular development.

Keywords: circular development; circular economy; spatial planning; resources; sustainability 
Much of the literature has concentrated on a neoliberal view of circular economy, which focuses on efficiency in supply and production processes to maximise profits for industry. In contrast the circular development pathway has wider societal goals which aim to improve the health of the urban ecosystem and those living in it.

This is achieved through a reduction in the consumption and wastage of resources (looping and adaptive actions) alongside the ecological regeneration of urban ecosystems (Williams, 2019a). It can produce a variety of ecological, health, community and economic benefits (Williams, 2021). Thus, it is an approach which sits comfortably within a socio-ecological transition.

In practice, the circular development pathway will prioritise reuse, recycling or energy recovery from residual resources (waste materials, water, heat, land and infrastructure). Urban ecosystem services will be enhanced to enable the recycling of water, soil, nutrients, gases and minerals. Cities will be designed (infrastructure and urban form) and communities encouraged to be adaptive, enabling urban systems to evolve with changing needs, whilst minimising the wastage of resources.

Looping, regenerative and adaptive actions are central to circular development. Designating space and infrastructure supportive of these three circular actions in the city-region is essential for the socio-ecological transition. As a key tool for regulating local development, spatial planning has a role to play in this transition process. However, in practice planning has an ambiguous legacy. 


\section{Creating space for low-value circular activities}

Self-identified "circular" cities are found in Europe (e.g. London, Paris, Amsterdam). These cities thrive economically and often use circular economy to further boost their competitiveness (Williams, forthcoming). However, their economic success, results in land and property speculation, which creates voids in cities (Sassen, 2015; Cashmore, 2015; United Nations 2017). This slows or even prevents the reuse of land and properties. It also prevents low-value activities, such as circular activities (Williams, 2019a).

There are many circular activities which require space in cities for example: the colocation of industries for industrial symbiosis; the storage of construction recyclables for future projects; urban farming enabling closure of the food waste loop and ecological regeneration. In space-scarce, high-value cities like London, speculation has resulted in the loss of industrial land to luxury commercial and residential development (Ferm and Jones, 2016). This creates a significant challenge for industrial symbiosis. Planning must intervene to ensure space is available for circular activities.

The economic viability of material reuse and recycling in cities, depends on the localisation of flows. For loops to be closed locally, the producers and "consumers" of "waste" should be co-located within the same city-region (Williams, 2019b). This may be impeded by a scarcity of potential consumers (e.g. industry and agriculture) in cities. In Paris the regional plan seeks to re-industrialise the city and protect farmland within the city region. The role of planning in localising industrial and food systems, to enable looping actions, is recognised both in the plan and circular economy strategy (Williams, forthcoming).

There may also be time-lags between the production and consumption of waste 
resources. Thus storage facilities and data platforms to enable resource exchange will be required to facilitate local circular resource flows. For example, in Amsterdam, the flows of construction "waste" are monitored (Circle Scan) and storage facilities provided, to support the creation of local supply chains (Circle Economy et al 2018). Planning and municipal procurement policies create a local market for recycled /reused construction materials, by requiring them to be used in construction (Williams, forthcoming).

Intervention is needed if circular activities are to compete for space in cities. In a neoliberal urban context, this may be achieved using temporary spaces for "pop-up" activities. In Paris, London and Amsterdam, temporary urbanism has been encouraged through the spatial plan. This has been further supported by the provision of temporaryuse contracts; databases identifying voids and potential user groups; imposition of tax on vacant sites and properties (Patti and Polyak, 2015).

In Paris there is now a reliance on temporary sites for urban agriculture. This has produced new forms of temporary farming, operated by not-for-profit community organisations (Demailley and Darly, 2017). Temporary activities are unlikely to produce the ecological and social benefits offered by the longer-term market gardening activities they replace (Demailley and Darly, 2017). Meanwhile larger sites with long leases are offered to commercial growers (e.g. Agropolis). Temporary, community projects find it difficult to compete with commercial activities, and often move off-site before they are established. Temporary spaces offer an opportunity for circular activities to emerge in land scarce cities, however, the commercial value of these activities must be demonstrated if they are to survive (Williams, forthcoming).

Temporary urbanism, is often hailed as a mechanism for transformation in a neoliberal 
context. However, it has variable results in making long-term adjustments within the urban system. Vacant sites often revert to high-value activities at the end of a lease (e.g Les Grands Voisins, Paris; Ladywell Pop-up village in London). Planning can intervene in land markets. It could allocate sites for circular activities on public land, offering longer leases. This will be necessary for circular activities to transform the urban economy.

\section{Infrastructure facilitating circular actions}

Infrastructure affects the production, distribution, assimilation and consumption of resources in cities (Chester and Allenby, 2017). It directly affects urban capacity for resource looping (e.g. grey-water recycling systems), adaptation (e.g. modular buildings) and ecological regeneration (blue-green infrastructure). Infrastructure also provides a source of materials and components. Thus, it should be designed for reuse or recycling. The renewal of a city provides opportunities to transform infrastructural systems. However, this is a slow process and there are many economic, institutional, technological, physical and cultural barriers (Williams, 2013; 2016 and 2019b).

Ideally infrastructure which fits within the existing context can reduce the inertia to adoption by the development regime. The ecocycles system in Stockholm, is a closedloop system which transforms material waste (sewage, household waste) and waste heat (from water treatment processes) into heating, biogas (used for cooking), biofuel (for public transport) and electricity. It utilises existing infrastructure (district heating system, CHP and thermal power station) with some new technologies for converting sludge into fertiliser, biogas and biofuel. It is underpinned by Stockholm's urban form (high density mixed-use development). The planning system ensures that the urban form and infrastructure continues to support ecocycles (Williams, 2013). It also 
encourages expansion by requiring that new developments connect to the system.

The planning process can also transform infrastructure. Amsterdam encouraged the development of circular infrastructure using circular land issue (release of public land) and tendering (contractual agreements). Circular principles were applied to new development, major refurbishments or demolition projects. One example is De Cuevel (Buiksloterham), an iconic project, constructed on a contaminated site in the Port of Amsterdam. It uses a variety of innovative solutions to deliver circular goals including: phyto-remediating plants to recycle the contaminated soil; dry composting toilets and separated urine collectors to produce fertiliser for local food crops; and decentralized helophyte filtration systems for grey-water recycling (Metabolic, 2014). It also recycled house-boats for workshops, offices and a café.

\section{Conclusion: the role for spatial planning in a socio-ecological transition}

The transition required to deliver circular development, will need spatial planning to go beyond the allocation of temporary spaces for circular experimentation. It will require planning to intervene in markets to provide space, long-term, for low-value, circular activities. This will also enable the localised looping of resources through the colocation of producers and consumers of "waste" within city-regions. Planning should support the delivery of infrastructure required to implement circular actions and ensure that urban form continues to support the systems adopted. It can also create demand for circular activities and products through requirements placed on new developments.

Thus, spatial planning will be critical to the socio-ecological transformation required in urban systems, to deliver circular development. 


\section{Bibliography}

Cashmore, Catherine (2015) Speculative Vacancies 8: The empty properties ignored by statistics. Published by Prosper: Australia.

Chester, Mikhail V., and Braden Allenby (2018) Toward adaptive infrastructure: flexibility and agility in a non-stationarity age. Sustainable and Resilient Infrastructure, pp.1-19.

Circle Economy, City of Amsterdam, and Copper8 (2018) Amsterdam Circular: Evaluation and action perspective, Report published by City of Amsterdam.

Demailly, Kaduna-Ève, and Ségolène Darly (2017) Urban agriculture on the move in Paris: The routes of temporary gardening in the neoliberal city. ACME: An International Journal for Critical Geographies, 16(2), pp.332-361.

Ferm, Jessica. and Jones, Edward., 2016. Mixed-use 'regeneration 'of employment land in the post-industrial city: challenges and realities in London. European Planning Studies, 24(10), pp.1913-1936.

Metabolic (2014) Circular Buiksloterham - Transitioning Amsterdam to a Circular city, 2014 Metabolic, Studio nine dots \& DELVA Landscape Architects.

Patti, Daniela, and Levente Polyak (2015) From practice to policy: frameworks for temporary use, Urban Research \& Practice, 8 (1), pp.122-134.

Sassen, Saskia (2015) Who owns our cities - and why this urban takeover should concern us all, Guardian Newspaper 24-11-2015.

https://www.theguardian.com/cities/2015/nov/24/who-owns-our-cities-and-why-thisurban-takeover-should-concern-us-all accessed 02-05-18.

United Nations (2017) Report of the special rapporteur on adequate housing as a component of the right to an adequate standard of living and on the right to nondiscrimination in this context $\mathrm{A} / \mathrm{HRC} / 34 / 51$.

Williams, Joanna (2013) The role of planning in delivering low-carbon urban infrastructure. Environment and Planning B: Planning and Design, 40 (4), pp.683-706. 
Williams, Joanna (2016) Can low carbon city experiments transform the development regime? Futures, 77, pp.80-96.

Williams, Joanna (2019a) Circular Cities: critical commentaries, Urban Studies, 56(13), pp.2746-2762.

Williams, Joanna (2019b) Circular cities: Challenges to implementing looping actions. Sustainability, 11(2), p.423.

Williams, Joanna. (forthcoming 2021) Circular Cities a revolution in Urban Sustainability, Published by Routledge: London. 
1

2

The role of spatial planning in transitioning to circular urban development Joanna Williams ${ }^{\text {a* }}$

${ }^{a}$ Bartlett School of Planning, University, College London, UK

Bartlett School of Planning, University College London, London WC1H 0NN, UK;

Correspondence: Loanna.williams@ucl.ac.uk 


\section{The role of spatial planning in transitioning to circular urban development}

Circular urban development necessitates the socio-ecological transformation of our urban systems. It requires that "wasted" resources - materials, water, heat, land and infrastructure - are looped; the ecological regenerative capacity and adaptive capacity of urban systems (infrastructure, form and communities) are developed. The end result will be healthier urban ecosystems, with low levels of resource consumption and wastage.

Spatial planning potentially has a crucial role to play in the delivery of circular urban development. However, it has an ambiguous legacy, as demonstrated by case studies in London, Paris and Amsterdam. Spatial planning will need to go beyond the allocation of temporary spaces for circular experimentation, if it is to enable the transition. It will need to intervene in markets to provide space for low-value, circular activities. This will also enable the localised looping of resources through the co-location of producers and consumers of "waste" within city-regions.

Spatial planning should further intervene, by supporting the infrastructure required to implement circular actions and ensuring that urban form continues to support the systems adopted. Planners can create demand for circular activities and products through requirements placed on new developments. Thus, spatial planning will be critical to the socio-ecological transformation, required in urban systems, to deliver circular development.

Keywords: circular development; circular economy; spatial planning; resources; sustainability 
Much of the literature has concentrated on a neoliberal view of circular economy, which focuses on efficiency in supply and production processes to maximise profits for industry. In contrast the circular development pathway has wider societal goals which aim to improve the health of the urban ecosystem and those living in it.

This is achieved through a reduction in the consumption and wastage of resources (looping and adaptive actions) alongside the ecological regeneration of urban ecosystems (Williams, 2019a). It can produce a variety of ecological, health, community and economic benefits (Williams, 2021). Thus, it is an approach which sits comfortably within a socio-ecological transition.

In practice, the circular development pathway will prioritise reuse, recycling or energy recovery from residual resources (waste materials, water, heat, land and infrastructure). Urban ecosystem services will be enhanced to enable the recycling of water, soil, nutrients, gases and minerals. Cities will be designed (infrastructure and urban form) and communities encouraged to be adaptive, enabling urban systems to evolve with changing needs, whilst minimising the wastage of resources.

Looping, regenerative and adaptive actions are central to circular development. Designating space and infrastructure supportive of these three circular actions in the city-region is essential for the socio-ecological transition. As a key tool for regulating local development, spatial planning has a role to play in this transition process. However, in practice planning has an ambiguous legacy. 


\section{Creating space for low-value circular activities}

Self-identified "circular" cities are found in Europe (e.g. London, Paris, Amsterdam). These cities thrive economically and often use circular economy to further boost their competitiveness (Williams, forthcoming). However, their economic success, results in land and property speculation, which creates voids in cities (Sassen, 2015; Cashmore, 2015; United Nations 2017). This slows or even prevents the reuse of land and properties. It also prevents low-value activities, such as circular activities (Williams, 2019a).

There are many circular activities which require space in cities for example: the colocation of industries for industrial symbiosis; the storage of construction recyclables for future projects; urban farming enabling closure of the food waste loop and ecological regeneration. In space-scarce, high-value cities like London, speculation has resulted in the loss of industrial land to luxury commercial and residential development (Ferm and Jones, 2016). This creates a significant challenge for industrial symbiosis. Planning must intervene to ensure space is available for circular activities.

The economic viability of material reuse and recycling in cities, depends on the localisation of flows. For loops to be closed locally, the producers and "consumers" of "waste" should be co-located within the same city-region (Williams, 2019b). This may be impeded by a scarcity of potential consumers (e.g. industry and agriculture) in cities. In Paris the regional plan seeks to re-industrialise the city and protect farmland within the city region. The role of planning in localising industrial and food systems, to enable looping actions, is recognised both in the plan and circular economy strategy (Williams, forthcoming).

There may also be time-lags between the production and consumption of waste 
resources. Thus storage facilities and data platforms to enable resource exchange will be required to facilitate local circular resource flows. For example, in Amsterdam, the flows of construction "waste" are monitored (Circle Scan) and storage facilities provided, to support the creation of local supply chains (Circle Economy et al 2018). Planning and municipal procurement policies create a local market for recycled /reused construction materials, by requiring them to be used in construction (Williams, forthcoming).

Intervention is needed if circular activities are to compete for space in cities. In a neoliberal urban context, this may be achieved using temporary spaces for "pop-up" activities. In Paris, London and Amsterdam, temporary urbanism has been encouraged through the spatial plan. This has been further supported by the provision of temporaryuse contracts; databases identifying voids and potential user groups; imposition of tax on vacant sites and properties (Patti and Polyak, 2015).

In Paris there is now a reliance on temporary sites for urban agriculture. This has produced new forms of temporary farming, operated by not-for-profit community organisations (Demailley and Darly, 2017). Temporary activities are unlikely to produce the ecological and social benefits offered by the longer-term market gardening activities they replace (Demailley and Darly, 2017). Meanwhile larger sites with long leases are offered to commercial growers (e.g. Agropolis). Temporary, community projects find it difficult to compete with commercial activities, and often move off-site before they are established. Temporary spaces offer an opportunity for circular activities to emerge in land scarce cities, however, the commercial value of these activities must be demonstrated if they are to survive (Williams, forthcoming).

Temporary urbanism, is often hailed as a mechanism for transformation in a neoliberal 
context. However, it has variable results in making long-term adjustments within the urban system. Vacant sites often revert to high-value activities at the end of a lease (e.g Les Grands Voisins, Paris; Ladywell Pop-up village in London). Planning can intervene in land markets. It could allocate sites for circular activities on public land, offering longer leases. This will be necessary for circular activities to transform the urban economy.

\section{Infrastructure facilitating circular actions}

Infrastructure affects the production, distribution, assimilation and consumption of resources in cities (Chester and Allenby, 2017). It directly affects urban capacity for resource looping (e.g. grey-water recycling systems), adaptation (e.g. modular buildings) and ecological regeneration (blue-green infrastructure). Infrastructure also provides a source of materials and components. Thus, it should be designed for reuse or recycling. The renewal of a city provides opportunities to transform infrastructural systems. However, this is a slow process and there are many economic, institutional, technological, physical and cultural barriers (Williams, 2013; 2016 and 2019b).

Ideally infrastructure which fits within the existing context can reduce the inertia to adoption by the development regime. The ecocycles system in Stockholm, is a closedloop system which transforms material waste (sewage, household waste) and waste heat (from water treatment processes) into heating, biogas (used for cooking), biofuel (for public transport) and electricity. It utilises existing infrastructure (district heating system, CHP and thermal power station) with some new technologies for converting sludge into fertiliser, biogas and biofuel. It is underpinned by Stockholm's urban form (high density mixed-use development). The planning system ensures that the urban form and infrastructure continues to support ecocycles (Williams, 2013). It also 
encourages expansion by requiring that new developments connect to the system.

The planning process can also transform infrastructure. Amsterdam encouraged the development of circular infrastructure using circular land issue (release of public land) and tendering (contractual agreements). Circular principles were applied to new development, major refurbishments or demolition projects. One example is De Cuevel (Buiksloterham), an iconic project, constructed on a contaminated site in the Port of Amsterdam. It uses a variety of innovative solutions to deliver circular goals including: phyto-remediating plants to recycle the contaminated soil; dry composting toilets and separated urine collectors to produce fertiliser for local food crops; and decentralized helophyte filtration systems for grey-water recycling (Metabolic, 2014). It also recycled house-boats for workshops, offices and a café.

\section{Conclusion: the role for spatial planning in a socio-ecological transition}

The transition required to deliver circular development, will need spatial planning to go beyond the allocation of temporary spaces for circular experimentation. It will require planning to intervene in markets to provide space, long-term, for low-value, circular activities. This will also enable the localised looping of resources through the colocation of producers and consumers of "waste" within city-regions. Planning should support the delivery of infrastructure required to implement circular actions and ensure that urban form continues to support the systems adopted. It can also create demand for circular activities and products through requirements placed on new developments. Thus, spatial planning will be critical to the socio-ecological transformation required in urban systems, to deliver circular development. 


\section{Bibliography}

Cashmore, Catherine (2015) Speculative Vacancies 8: The empty properties ignored by statistics. Published by Prosper: Australia.

Chester, Mikhail V., and Braden Allenby (2018) Toward adaptive infrastructure: flexibility and agility in a non-stationarity age. Sustainable and Resilient Infrastructure, pp.1-19.

Circle Economy, City of Amsterdam, and Copper8 (2018) Amsterdam Circular: Evaluation and action perspective, Report published by City of Amsterdam.

Demailly, Kaduna-Ève, and Ségolène Darly (2017) Urban agriculture on the move in Paris: The routes of temporary gardening in the neoliberal city. ACME: An International Journal for Critical Geographies, 16(2), pp.332-361.

Ferm, Jessica. and Jones, Edward., 2016. Mixed-use 'regeneration 'of employment land in the post-industrial city: challenges and realities in London. European Planning Studies, 24(10), pp.1913-1936.

Metabolic (2014) Circular Buiksloterham - Transitioning Amsterdam to a Circular city, 2014 Metabolic, Studio nine dots \& DELVA Landscape Architects.

Patti, Daniela, and Levente Polyak (2015) From practice to policy: frameworks for temporary use, Urban Research \& Practice, 8 (1), pp.122-134.

Sassen, Saskia (2015) Who owns our cities - and why this urban takeover should concern us all, Guardian Newspaper 24-11-2015. https://www.theguardian.com/cities/2015/nov/24/who-owns-our-cities-and-why-thisurban-takeover-should-concern-us-all accessed 02-05-18.

United Nations (2017) Report of the special rapporteur on adequate housing as a component of the right to an adequate standard of living and on the right to nondiscrimination in this context $\mathrm{A} / \mathrm{HRC} / 34 / 51$.

Williams, Joanna (2013) The role of planning in delivering low-carbon urban infrastructure. Environment and Planning B: Planning and Design, 40 (4), pp.683-706. 
Williams, Joanna (2016) Can low carbon city experiments transform the development regime? Futures, 77, pp.80-96.

Williams, Joanna (2019a) Circular Cities: critical commentaries, Urban Studies, 56(13), pp.2746-2762.

Williams, Joanna (2019b) Circular cities: Challenges to implementing looping actions. Sustainability, 11(2), p.423.

Williams, Joanna. (forthcoming 2021) Circular Cities a revolution in Urban Sustainability, Published by Routledge: London. 